\title{
Context and dynamics of same-sex behavior among long- distance truckers in India: Findings from qualitative research
}

Vaishali Sharma Mahendra

Population Council

Ravi K. Verma

Population Council

Pertti J. Pelto

Sarat Chandra Pradhan

Population Council

Vibha Singh

See next page for additional authors

Follow this and additional works at: https://knowledgecommons.popcouncil.org/departments_sbsr-hiv

Part of the Family, Life Course, and Society Commons, Gender and Sexuality Commons, and the International Public Health Commons

How does access to this work benefit you? Let us know!

\section{Recommended Citation}

Mahendra, Vaishali Sharma, Ravi K. Verma, Pertti J. Pelto, Sarat Chandra Pradhan, Vibha Singh, Asha Rao, and Tarun Vij. 2006. "Context and dynamics of same-sex behavior among long-distance truckers in India: Findings from qualitative research." New Delhi: Population Council. 


\section{Authors}

Vaishali Sharma Mahendra, Ravi K. Verma, Pertti J. Pelto, Sarat Chandra Pradhan, Vibha Singh, Asha Rao, and Tarun Vij 


\section{Context and dynamics of same-sex behavior among long-distance truckers in India}

Findings from qualitative research

Vaishali S Mahendra ${ }^{1}$, Ravi Verma ${ }^{1}$, Pertti Pelto ${ }^{2}$, Sarat Pradhan ${ }^{1}$, Vibha Singh ${ }^{3}$, Asha $\mathrm{RaO}^{3}$, Tarun $\mathrm{Vij}^{3}$

Population Council

Transport Corporation of India Foundation

2006

Institutional affiliations at the time of the study: ${ }^{1}$ Population Council; ${ }^{2}$ Independent Consultant;

${ }^{3}$ Transport Corporation of India Foundation 


\section{Kavach

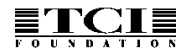

TCI Foundation implements Project 'Kavach', a national health \& HIV/AIDS prevention program for long distance truckers at 17 major locations across 9 states.

\section{(1) Population Council}

The Population Council is an international, non-profit, nongovernmental institution that seeks to improve the well-being and reproductive health of current and future generations around the world and to help achieve a humane, equitable, and sustainable balance between people and resources. The Council conducts biomedical, social science, and public health research and helps build research capacities in developing countries. Established in 1952, the Council is governed by an international board of trustees. Its New York headquarters supports a global network of country offices.

(C) Population Council 2006

Suggested citation: Mahendra V.S., Verrma R., Pelto P., Pradhan S., Singh V., Rao A., and Vij T. (2006) “Context and dynamics of same sexual behaviors of long distance truckers in India: Findings from qualitative research." Population Council, New Delhi, India.

For more information, please contact:

Population Council

142 Golf Links, First Floor

New Delhi - 110 003, India.

Tel: 91-11-41743410/11; 24651314

Fax: 91-11-41743412

Email: horizons-india@popcouncil.org

www.popcouncil.org

Transport Corporation of India Foundation

TCI House

69 Institutional Area, Sector 32

Gurgaon - 122 001, Haryana, India

Tel: 91-124-2381603-07

Fax: 91-124-2384086

www.grouptci.com 


\section{Contents}

Acknowledgement $\quad \mathrm{v}$

Acronyms and Abbreviations $\quad$ vi

Executive Summary $\quad$ vii

Introduction 1

Research Methodology 5

Sex Partners and Sexual Behavior of Truckers Involved in MSM Activities 9

Health Problems and Treatment Seeking 22

$\begin{array}{ll}\text { Discussion } & 25\end{array}$

Implications for Intervention Programs and Further Research $\quad 27$

References 31 



\section{Acknowledgments}

The research was implemented by the Population Council with financial support from the Transport Corporation of India Foundation (TCIF) under the aegis of Avahan, the India AIDS Initiative funded by the Bill and Melinda Gates Foundation. The research team comprised of Ravi Verma, Vaishali S Mahendra and Sarat Pradhan of the Population Council and Asha Rao and Vibha Singh formerly of the TCIF. Technical assistance and support in data analysis and report writing was provided by Pertti J. Pelto. Tarun Vij of TCIF undertook careful review of the study report and provided insightful inputs to finalize it.

The research team would like to acknowledge the cooperation and support extended by the five partner NGOs in assigning staff members to implement the study in their sites. Chandrashekhar Rai (Society for Social Service, New Delhi), Rabindra Nahak (Bhoruka Public Welfare Trust, Ichhapuram), Sanjay Kumar (Jan Kalyan Maha Samiti, Varanasi), Damodar Rao (Bhoruka Charitable Trust, Bangalore) and Jai Ram (Ambika Niketan Trust, Surat) were the driving force of the study. Without their skillful data collection, this study would not have been possible. Thanks are due to TCIF's regional program coordinators, Tanvir Rizvi and Lakshmi Narain, for supervising data collection in their project sites. We would also like to thank Gina Dalabetta, Virginia Loo and Aparajita Bhalla of Avahan India AIDS Initiative for their valuable inputs in strengthening the research design and training of the research team.

Our deep appreciation to Dr. Saroj Pachauri, Population Council, for her guidance and support in designing and implementing the study. We would like to acknowledge the able administrative support extended by Mr. V. L Thomas of Population Council throughout the study. Thanks also to the team of Mosaic Publishing for assisting in editing, formatting and printing of the report.

Finally we would like to express our gratitude to all the study respondents who opened up and shared their intimate experiences and personal opinions on sensitive and taboo issues to enrich our understanding. 


\section{Acronyms and Abbreviations}

$\begin{array}{ll}\text { AIDS } & \begin{array}{l}\text { Acquired Immune Deficiency Syndrome } \\ \text { APAC }\end{array} \\ \text { BCC } & \text { BIDS Prevention and Control Society } \\ \text { CBO } & \text { Community Based Organization } \\ \text { DFID } & \text { Department for International Development (UK) } \\ \text { HIV } & \text { Human Immunodeficiency Virus } \\ \text { MSM } & \text { Men who have Sex with Men or Male-to-Male Sex } \\ \text { NGO } & \text { Non Government Organization } \\ \text { ORG } & \text { Operations Research Group } \\ \text { STI } & \text { Sexually Transmitted Infection } \\ \text { STD } & \text { Sexually Transmitted Disease } \\ \text { TCIF } & \text { Transport Corporation of India Foundation } \\ \text { VHS } & \text { Voluntary Health Services }\end{array}$




\section{Executive Summary}

It is well established that truckers (this term refers to drivers and helpers) have higher rates of non-marital sex than any other occupational group. Because of this multi-partner sexual activity, truckers form a key group of prevention efforts for HIV and Sexually Transmitted Infections (STI). Thus far, HIV/STI prevention interventions for truckers have been geared to providing risk-reduction information and services within a heterosexual context. Recent evidence, though anecdotal, suggests that a significant number of truckers engage in male-to-male (MSM) sexual activity which has implications for HIV/STI transmission. Therefore, information on the nature and extent of MSM activity among these populations is urgently needed for the design and implementation of comprehensive prevention programs for truckers.

The Transport Corporation of India Foundation (TCIF) is implementing Project Kavach to reduce HIV/ STI vulnerability among 1.5 million truckers and their partners in the country. TCIF's targeted intervention has been largely aimed at preventing HIV related risk of truckers by promoting safe sexual behaviors within a heterosexual context. Recognizing the need to strengthen its program efforts to include information and services to address this aspect of sexual risk, TCIF collaborated with Population Council to undertake an exploratory study to understand the dynamics of same sexual behavior of truckers. Evidence from this research will guide TCIF in designing appropriate program strategy and activities to provide comprehensive HIV/STI prevention services to their key population of truckers. Some of the key questions explored during the research were: Who are the male sexual partners of truckers? What is the risk involved in same-sex behavioral activities? What factors influence same sex behaviors of truckers? What are programmatic and research implications?

A desk-based review of the existing literature on sexual behavior and HIV/STI vulnerability among truckers was carried out. This was complemented by field research in selected halt points of truckers where Project Kavach is being implemented. At the time of conduct of the study, Project Kavach was being implemented in 11 sites across the country. Of these 11 sites, five sites that provided a regional distribution of truckers were selected for undertaking the field research. These sites included Azadpur Mandi in New Delhi, Chandausi in Uttar Pradesh, Ichhapuram in Andhra Pradesh, Nelamangala in Karnataka and Surat in Gujarat. Outreach workers from TCIF's partner organizations in each of the study sites were trained to conduct a total of 32 in-depth interviews with drivers and their helpers who reported that they 
engaged in MSM activities. In addition, 39 key informant interviews and 11 focus group discussions were conducted with drivers, helpers, brokers, male sex partner and the other allied populations found at the various trucking halt points.

Study findings suggest that MSM activity among truckers appears to be widespread. Different types of male sex partners are involved and the locations and situations for MSM activities are extremely diverse. For both drivers and helpers, sex with hijras emerged as a dominant pattern followed by sex with khalasis (helpers), young boys, feminized men and with a unique category of 'bawasir' (men who complain of anal/rectal itching and get relief from being penetrated in anal intercourse). MSM activity between drivers and khalasis was strongly affected by the power relationship as khalasis are dependent on the truck drivers for employment and monetary gain. Anal penetration was the predominant sexual act and anal sex with men was not only described as safe but also pleasurable. However, a large proportion of truckers also sought extensive non-penetrative sexual acts with their same sex partners. Several truckers expressed a strong compulsion to engage in same sex activities and mentioned various reasons for doing so. Many drivers and helpers proactively sought out other men for sex. Another reason given was "women are carriers of HIV and therefore unsafe."

The truckers did not clearly see a connection between STIs and HIV and did not mention the need to recognize and/or prevent STIs. On the contrary, they delayed seeking treatment for STI symptoms or sought inappropriate treatment. They were aware of HIV, the various modes of its transmission and prevention strategies. However, what is of programmatic significance is that condoms were used very infrequently in same sexual encounters even though most of the truckers were aware of the importance of condoms for protection during vaginal sex with female sex workers.

This qualitative study identifies the patterns of same-sex sexual behavior of truckers that need to be addressed in HIV-prevention interventions. It appears that truckers may be reducing contacts with female sex workers, and are instead seeking male sexual partners. These changes may be a result of interventions which have placed a heavy emphasis on female sex workers as the primary sources for the spread of HIV infection. Truckers also believe that anal sex is 'safe sex' and thus do not perceive the need to use condoms during same sex penetrative sexual acts. These misconceptions, a reflection of the ways in which information about safe sexual practices is conveyed through AIDS awareness and outreach campaigns must be corrected to prevent the transmission of HIV infection.

Building on this study, additional research needs to be carried out to better understand associated HIV related risk to truckers and their partners and enhance program interventions. Some suggested research ideas include assessing magnitude of same sex behaviors among truckers; studying sexual networking patterns of truckers to examine the concurrency of male and female sexual partners and HIV risk among truckers; understanding the dynamics of coercive and non-consensual sex among truckers and their partners; exploring the role of substance use such as alcohol and drugs and related HIV risk; documenting the nature of HIV risk for different categories of truckers depending on their nature of work contract (long-distance or shortdistance truckers), regional background, etc. 


\section{Introduction}

Throughout the world, current statistical information shows that HIV infections are spread largely through heterosexual intercourse, simply because acts of malefemale sexual intercourse are of very high frequency compared to all other behaviors through which the HIV infection can be spread. For example, needlesharing among injecting drug users has a much higher probability of HIV transmission (in any one act) than does heterosexual intercourse, but the numbers of persons engaged in that activity are a small minority in all populations. Male-to-male sexual intercourse is much less frequent (in total numbers) than heterosexual contacts, but it has long been noted that some of the sexual behaviors of persons who engage in male-to-male sex (or men who have sex with men (MSM) ${ }^{1}$ make them particularly vulnerable to HIV infections. The transmission rates per sex act are much higher for anal sex than for vaginal sex, because the membranes in the anal region are easily damaged; hence there is much greater likelihood of transmission of body fluids into the bloodstream.

The taboos on discussion of same-sex activities remain strong, and have deterred serious datagathering until recently the seriousness of the HIV/ AIDS pandemic caused research on MSM behaviors to assume high priority. Pioneering efforts by the Humsafar Trust, the Naz Foundation International, and researchers in several regions of India have resulted in increased awareness, and considerable new descriptive data about MSM, particularly in major cities (Row-Kavi 1993; Khan 1994; Asthana and Oostvogels 2001; Humsafar Trust 2002; Kulkarni et al. 2004; Ramakrishna et al. 2004). While most of the research on MSM populations in India has been carried out in urban locations, a recent survey of sexual behaviors in five states has shown that approximately 10 per cent of unmarried men in rural areas reported MSM activity in the past year (Verma and Collumbien 2004).

\footnotetext{
${ }^{1}$ Men who have sex with men - frequently shortened to MSM in the literature - is used to refer to all male-tomale sex. MSM is used primarily to refer to behaviors and does not suggest any specific sexual identity or orientation of individuals. Many men who have sex with men do not consider themselves gay or bisexual and thus the behavioral term MSM has gained wide acceptance in the HIV/AIDS literature. (UNAIDS www.unaids.org).
} 
The data presented in these sources make it very clear that MSM activities are highly secretive, and involve a wide range of different types of males, with complex variations in sexual orientations and practices. Researchers such as Asthana and Oostvogels, Kulkarni et al., Row-Kavi, and others, have repeatedly emphasized the extent to which MSM patterns in India are much different from "the gay scene" in Europe and America. Asthana and Oostvogels, in describing MSM activities in Chennai, emphasized the fact that "gay identity" is extremely rare among the men involved in same-sex activities; and Kulkarni et al. found the same generalization applied in western Maharashtra. Row-Kavi's materials from Mumbai, on the other hand, give a glimpse of more "westernized" predominantly middle-class men, some of whom self-identify as "gay," as reflected in the pages of the newsletter, Bombay Dost.

The recent research on MSM activities and subgroups in India focuses attention on the importance of two categories of people who are especially active as male sex workers: the hijras and kothis. Although hijras are often referred to as a "third sex," in most discussions of MSM activity they are generally subsumed in the male category (Asthana and Oostvogels 2001; Chakrapani et al. 2002). (Many other names are used as labels for hijras, including the term, "Ali" among Tamil speakers.) Kothis "are males who are 'effeminate' in their demeanor, often adopting feminine 'code-names,' using women's make-up and sometimes dressing as women. They usually adopt the role of being penetrated in sexual encounters" (Ramakrishna et al. 2004:60). The label kothi is widely used by the kothis themselves, and is known throughout much of India. Other terminology is also found, and the corresponding label in Orissa and West Bengal is usually "maichia." Asthana and Oostvogels have found the word, danga to be widely current in Chennai as a label for an effeminate man who engages in MSM activities, apparently referring to the same type of men elsewhere referred to as kothis.

Throughout India, the more effeminate types of males (hijras and kothis) use the word panthi to refer to their masculine clients, who are the "penetrators" in sexual encounters. Whereas labels such as kothi and danga are used by the persons to identify themselves, the panthi label is used to identify "those others." The clients of hijras and kothis do not usually self-identify as panthis, as they are persons who are "ordinary males" in their own social circles. Most anecdotal evidence suggests that these customers of male sex workers come from a wide range of sectors of Indian society. Some are college men seeking sexual experience, some are day laborers and truckers, and quite many are middle-class businessmen and office workers.

In addition to these recognized, labeled types of "effeminate" or "feminized" males involved in MSM activities, all the recent studies refer to a number of other types of "unlabeled" males who also participate in MSM activities. These include many "street children" (Ramakrishna et al. 2004), males in prisons, hostels, army barracks and other institutional settings, "hotel boys," boys in dhabas and other roadside establishments, and many others. Thus, the sub-groups of males involved in MSM sexual activities range from the quite "visible" hijras and 
some kothis, to the invisible panthis and others who are often married with families; as well as the many other types who are involved in various ways in male same-sex activities.

\section{Sexual behavior of truckers ${ }^{2}$}

The growing literature on patterns of MSM activities in India is very much urban-oriented, and includes very little mention of truckers and other non-urban sectors of Indian society.

Throughout most parts of the world, it has been found that trucker populations have much higher rates of extramarital sex contacts than almost any other population sector. In Africa, for example, it has long been noted that truck routes are major arteries for the spread of HIV infections, and truckers are primary agents in the transmission of infections because of their high frequencies of multi-partner sexual activities (Von Reyn 1990; Orobuloye, et al. 1992). Closer to India, recent surveys of truckers and other male populations in Nepal found that truckers had much higher rates of contact with sex workers and other extramarital partners, as compared to migrant workers and policemen, for example (New Era 2002).

Several studies in the early 1990s of truckers along Indian highways found that 75 per cent or more of both drivers and helpers engage in extramarital sexual activities in the course of their travels (Singh et al. 1991; Ahmed 1992; Rao et al. 1994). The most obvious reason for their high rates of recourse to sex

\footnotetext{
${ }^{2}$ The term 'truckers' refers to both drivers and helpers.
}

workers and other extramarital partners is that their work generally requires that they are away from wives and families for long periods of time. In addition, some of the studies report that the truckers consider the conditions of their work, particularly exposure to hot weather and heat from the truck motors, to require release through sexual activity; also "tiredness caused by driving demands sexual relief" (Rao et al. 1994).

More recent surveillance data among truckers in south India (Tamil Nadu) show a decrease in the rates of extramarital sexual activity during the surveillance period from 1996 to 2002 (APAC 2002). The surveillance surveys reported sexual intercourse with non-regular partners to be practiced by 48 per cent of all truckers surveyed in 1996, declining to 27 per cent in 2002. In contrast to the earlier studies, the truckers in the Tamil Nadu surveys reported high rates of knowledge of HIV/AIDS and STIs, and also high rates of condom use, reaching over 90 per cent in cases of "paid sex," but only 37 per cent in instances of "casual sex." However, those data may appear to involve some under-reporting, as they show only 2 per cent or less of MSM activities (APAC 2002). In contrast, a recent study in three cities of Jharkhand, carried out by ORG researchers, found that 8 per cent of the truckers reported MSM activities, with a high of 14 per cent in the sample at Ranchi (ORG 2003). The figure of 8 per cent is still low, as compared to the data from earlier studies in northeastern India, which reported 15 per cent MSM activity among the 527 truckers interviewed (Ahmed 1992). The study, also in 
eastern India, by Rao and colleagues (1994), found

that 30 to 40 per cent of the informants (drivers and khalasis) reported engaging in oral and/or anal sex with male partners. A more recent study commissioned by TCIF at Nelamangala Halt Point outside Bangalore indicates that 83 percent of the truckers interviewed were aware that drivers/helpers have sex with men (Synovate, 2004). However, this study does not reflect the prevalence and context of same-sex behaviors among the trucker population.

The earlier reports of MSM activities among truckers referred to sex between drivers and their khalasis (helpers), and occasionally, with other drivers. Secondarily there was some mention of sex workers, but sex with hijras was not mentioned. According to Nag's discussion on hijras, they are found mainly in or near urban areas (Nag 1996).

\section{Generalizations about truckers and sexual activities}

Based on the available studies, the following features emerge concerning the trucking population in India:

a. Truckers are generally reported as having much higher rates of non-marital sex than any other occupational group (Singh et al. 1991; Ahmed 1992; Rao et al. 1994). b. Their non-marital sex is usually explained as "caused by" the long periods of absence from their wives and families, while they are "on the road."

c. Addition reasons give by some truckers are the "heat" (garmi) that is generated in their bodies during their truck driving; and also the provocations from the easy availability of sex workers along the highway (especially at their highway halt places).

d. Although no previous studies have focused directly on truckers' MSM activities, a few studies have pointed to the prevalence of these. The study by Rao and colleagues (1994) is the prime example.

Thus it is clear that information on MSM activity among the trucker populations is urgently needed for the design and implementation of comprehensive HIV/STI prevention programs for truckers. In recognition of this need, the Transport Corporation of India Foundation (TCIF), currently implementing Project Kavach, an HIV / STI prevention program for long distance truckers, collaborated with the Population Council to better understand the patterns and context of same-sex sexual activity among longdistance truck drivers. 


\section{Research Methodology}

The Project Kavach of TCIF is being implemented under the aegis of Avahan (the India AIDS Initiative funded by the Bill and Melinda Gates Foundation) with the aim of reducing the HIV/STI vulnerability of 1.5 million long distance truckers (drivers and helpers) and their partners. The project covers 17 major transshipment/transport centers in 9 states and is implemented in collaboration with 15 partner Non Government Organizations (NGOs). The major elements of the program include STI management through Khushi clinics at the truck points, Behavior Change Communication (BCC) and Condom Promotion. However, as TCIF's current efforts are largely aimed at heterosexual behaviors and interactions of truckers, this collaborative research study will fill in the gaps in data and efforts aimed at understanding the context and dynamics of samesex behaviours of truckers. It is expected that study findings will enable the development of contextspecific interventions to reduce truckers risk behaviours.

\section{Study objectives and research questions}

The overall objective of the study was to understand specifically the context and dynamics of same-sex behaviors among truckers. In particular the study attempted to address the following three key questions:

i. Who are the male sex partners of truckers? To enlist and understand who the various male sex partners of truckers (drivers and helpers) are and whether they are from within the trucking community or from outside.

ii. What are the reasons for accessing these male sex partners? To explore the factors that may influence truckers in same-sex sexual behavior and their access to male partners.

iii. What is the nature of sexual risk involved in samesex sexual activity? To understand the nature and extent of partner mixing as well as types of sexual acts that truckers engage in with their male sexual partners. Other questions that were explored related to this key theme were - What is the truckers perception about these sexual acts in terms of pleasure and safety, and what is their perception on the use of condoms in these acts? In addition, their knowledge and attitudes about HIV and treatment seeking for STIs were also examined. 


\section{Study methods}

The researchers undertook two distinct yet mutually supporting activities simultaneously as part of this assignment to collect responses to the key questions:

Review and compilation of existing literature and information, both published and unpublished, on sexual behavior and HIV/STI vulnerability of truckers in India, with a focus on same-sex behaviors and activities among men. We collected and collated relevant papers, reports, presentations, and other publications from various donors, international and national NGOs and Community Based

Organizations (CBOs) within the country. Some of the organizations who were contacted for their reports and work with truckers and/or with men who have sex with men specifically are DFID, VHS-APAC, AVERT, Bhoruka Welfare Trust, Bharosa, Naz Foundation International and Humsafar Trust.

Field-based qualitative research to understand the dynamics and context of same-sex sexual behavior. To complement the desk-based review this aspect of the research entailed primary data collection from a range of respondents that included truckers (drivers, helpers and cleaners), health care providers, program implementers from NGOs and CBOs, and a few sexual partners of truckers.

Table 1: Study sites

\begin{tabular}{llll}
\hline State & NGO partner & Site & Type of halt point \\
\hline New Delhi & Society for Social Service & Azadpur Mandi & Fruit and vegetable market \\
Uttar Pradesh & Jan Kalyan Maha Samiti & Chandausi & Coal depot \\
Andhra Pradesh & Bhoruka Public Welfare Trust & Ichhapuram & Checkpost \\
Karnataka & Bhoruka Charitable Trust & Nelamangala & Trans-shipment colony \\
Gujarat & Ambika Niketan Trust & Surat & Industrial area \\
\hline
\end{tabular}

\section{Selection of field research sites}

In its first phase of implementation, TCIF's Project Kavach was implemented in 11 sites in India. For the purpose of the field research, five of these sites were selected to provide a regional distribution of truckers. The criteria used for selection of sites included volume of trucks passing through the site or halt point close by, duration of truckers' stay at the site, and access to and utilization of program/project services by truckers in and around the sites. The sites were selected after discussion and consultation with TCIF, and are listed in Table 1.

\section{Selection and training of research team}

From each of the study sites, researchers were recruited from the NGOs currently working with TCIF in implementing project Kavach. It was decided that as the NGO has an established rapport with the trucking community it would be easier for the researcher to probe for information on sensitive and taboo issues such as same-sex behaviors. The researchers were given training to enhance their knowledge and sensitize them towards issues relating to same-sex sexual behavior, data collection methods and ethical principles. Study investigators provided ongoing support and supervision of the interviewers. 


\section{Selection of respondents and data collection}

From each of the sites, various members of the trucking community were interviewed, including drivers and helpers and cleaners, as well as brokers, mechanics, garage owners and dhabawalas (eating place managers) located at the truck halt sites. In addition, health care providers and same-sex partners were also identified as key respondents for inclusion in the study.

The qualitative data collection methods included social mapping, free-listing, focus group discussions, key-informant interviews and in-depth interviews as shown in Table 2. Data collection guides were finalized following pre-testing by the research team. Informed consent forms were developed and translated in local languages for ethical enrolment of respondents.

To enhance rapport with the trucking community the researchers first conducted social mapping in their study sites. In this activity they engaged drivers, helpers, mechanics, brokers, and others to draw physical maps of their areas and to identify various points where truckers engage in social activities during their leisure time. This was helpful in opening up discussions regarding the sexual behavior of truckers. Through this activity, the researchers were able to identify key informants for further probing on the truckers' same-sex behaviors. Key-informant interviews were conducted with drivers, helpers, brokers, mechanics and health care providers to better understand the patterns of same-sex behavior in their community. Some of the key informants also aided in introducing the researchers to drivers and helpers who had engaged in same-sex behaviors. Upon receiving written informed consent from these drivers and helpers, in-depth interviews were conducted with them to learn about their same-sex experiences. In addition, the researchers conducted focus group discussions with drivers, helpers and brokers to understand the community's perceptions about same-sex behavior. Free-listings were also conducted to get an understanding of the range of sex partners and an "inventory" and vocabulary of same-sex acts.

Table 2 provides illustrative questions and methods of data collection that were used for the different categories of respondents.

\section{Data management and analysis}

All the interviews were tape-recorded after taking the permission of the respondents. The researchers also took detailed field notes which supplemented the taped interviews. Extreme care was taken by the researchers to ensure the confidentiality of the respondent. The tapes were kept safely in the custody of the researchers. The identity of respondents was not included in the interview transcripts which insured their anonymity.

The interviews were conducted in the local language, and then transcribed into handwritten notes by the researchers following which each transcript was translated and typed in English for analysis. Study investigators reviewed the transcripts and developed a detailed code list for analysis. Data from in-depth and key-informant interviews were entered into ATLAS/Ti and analyzed using the code 
list. Free lists were translated and collated and then

entered into the ANTHROPAC software program, for generation of frequencies and ratings of the

"salience," or "centrality" of the items.

Table 2: Data collection framework

\begin{tabular}{|c|c|c|}
\hline Data collection methods & Respondent and sample size & Areas of inquiry \\
\hline In-depth interviews & $\begin{array}{l}\text { Total }-32 \\
\text { (Drivers - 24, Helpers - 8) }\end{array}$ & $\begin{array}{l}\text { Sexual behavior and experiences of truckers } \\
\text { engaged in same-sex activities. Sexual } \\
\text { interaction with male partners. Types of male } \\
\text { partners. Type of relationship with male } \\
\text { partners. Types of sex acts, condom and } \\
\text { lubricant use. Barriers to condom and } \\
\text { lubricant use. Factors influencing for same- } \\
\text { sex acts/partners. Violence-experienced and } \\
\text { perpetrated. Level of knowledge regarding } \\
\text { HIV/AIDS and STIs. Health seeking behavior } \\
\text { for STIs. }\end{array}$ \\
\hline Key-informant interviews & $\begin{array}{l}\text { Total - } 39 \\
\text { (Drivers - 16, Helpers - 13, } \\
\text { Brokers -5, Health Providers - 2, } \\
\text { Same-sex Partners - 3) }\end{array}$ & $\begin{array}{l}\text { Perspectives on magnitude and patterns of } \\
\text { same-sex sexual behaviors of truckers. } \\
\text { Special health concerns for truckers who } \\
\text { engage in same-sex sexual behaviors. } \\
\text { Knowledge and attitudes pertaining to STI } \\
\text { and HIV/AIDS and sexuality. }\end{array}$ \\
\hline Focus group discussion & $\begin{array}{l}\text { Total - } 11 \\
\text { (Drivers - 4, Helpers - 3, } \\
\text { Brokers - 4) }\end{array}$ & $\begin{array}{l}\text { Perspectives on the magnitude and patterns } \\
\text { of same-sex sexual behavior of truckers in } \\
\text { the program areas }\end{array}$ \\
\hline Free-listing & $\begin{array}{l}\text { Total - } 98 \text { (for listing of } \\
\text { same sex partners) } \\
\text { Total - } 111 \text { (for listing of } \\
\text { same-sex acts) } \\
\text { (Free lists were generated as part } \\
\text { of in-depth and key informant } \\
\text { interviews. In some cases } \\
\text { mechanies, tea-stall/dhaba wallas, } \\
\text { and NGO outreach workers were } \\
\text { also asked to generate free-lists). }\end{array}$ & $\begin{array}{l}\text { Listing of same-sex partners and same-sex } \\
\text { acts. }\end{array}$ \\
\hline
\end{tabular}




\section{Sex Partners and Sexual Behavior of Truckers Involved in MSM Activities}

Early in the data collection the researchers asked a series of different informants to list "the types of persons with whom the truckers have sex." The informants were "tea-stall walas," mechanics, vendors, truckers, as well as other persons such as brokers, etc., who are familiar with truckers because of their activities at the truck halt areas. The resulting data, in Table 3, show the kinds of sex partners most frequently mentioned by the informants. In addition to showing the relative frequencies of the different categories of partners, the analysis of the lists also takes into account the "average rank." Average rank focuses on whether individual informants listed a particular type of partner near the beginning of their list, or later. If all informants mentioned a particular type of partner as the very first item in their list, then the "average rank" would be 1.0. That "average rank" measure is used in conjunction with the frequency of the items, to arrive at an overall "salience score" (Smith's S), which can be regarded as a measure of the "centrality" of an item in people's thinking. Thus, in Table 3, "hijras" are the "most salient" or "central" as sex partners, not only based on frequency of mention (79 per cent of respondents) but also based on the "higher Smith's S," (0.567 - closer to 1.0 than the other items listed).

In Table 3, we have presented the top 20 types of sex partners from a total of 50 listed by 98 respondents. 'Hijra' tops the list of sex-partners followed by 'helper', 'randi', 'female' and 'launda'.

Males, of various categories, appear to be the salient sex partners of truckers. If we examine the top 15 "types of sex partners," only three are females: number 3 "randi" (sex worker), number 4 "female," and number 12 "female beggars." Another indication of the salience of males as sex partners is that only six items in the entire list clearly refer to females. Of all the 20 partners listed, while there are a few types of partners that could be of either sex (e.g. laborers, fashion designers, doctors and "children who beg"), by far the largest number of different "types" are males (15 different categories.).

The "top five" types of partners, according to the informant listings certainly give a prominent place to females, both sex workers and the undifferentiated label, "females." On the other hand, hijras appear to play a very important part in the sexual practices of many truckers. It is not surprising that the item two 
Table 3. Types of sex partners of truckers, as listed by key informants (Number of informants: 98)

\begin{tabular}{|c|c|c|c|c|c|}
\hline & Item & Frequency Resp & $\%$ & Avg Rank & Smith's S* \\
\hline 1 & $H I J R A$ & 77 & -- & 2.208 & 0.567 \\
\hline 2 & HELPER & 69 & 7 & 2.681 & 0.427 \\
\hline 3 & $R A N D I$ & 40 & 41 & 2.350 & 0.287 \\
\hline 4 & FEMALE & 38 & 39 & 2.553 & 0.251 \\
\hline 5 & LAUNDA & 26 & 27 & 3.423 & 0.130 \\
\hline 6 & GANDU & 24 & 24 & 2.792 & 0.152 \\
\hline 7 & BOY & 17 & 17 & 3.059 & 0.095 \\
\hline 8 & MALE & 16 & 16 & 2.250 & 0.115 \\
\hline 9 & BAWASIR & 15 & 15 & 3.867 & 0.073 \\
\hline 10 & DRIVER & 8 & 8 & 2.750 & 0.053 \\
\hline 11 & КОТНI & 7 & 7 & 2.714 & 0.045 \\
\hline 12 & FEMALE BEGGAR & 5 & 5 & 3.600 & 0.022 \\
\hline 13 & СННАКА & 5 & 5 & 2.400 & 0.034 \\
\hline 14 & BOY VENDOR & 4 & 4 & 3.250 & 0.018 \\
\hline 15 & CHOKRI & 4 & 4 & 2.000 & 0.030 \\
\hline 16 & PAUNE AATH & 4 & 4 & 2.500 & 0.020 \\
\hline 17 & HIJRI & 3 & 3 & 5.000 & 0.015 \\
\hline 18 & BOYS WORKING IN THE DHABA & 3 & 3 & 4.333 & 0.009 \\
\hline 19 & DHANDHA WALA & 2 & 2 & 5.000 & 0.005 \\
\hline 20 & MALISHWALA & 2 & 2 & 3.500 & 0.011 \\
\hline
\end{tabular}

* The meaning of "Smith's S" is most clear if we examine the scores for items number 12 and 13 in the list. Although both these "types" are listed by 5 respondents, female beggar is "less salient," as it was, on average, closer to fourth in people's lists (average rank 3.60) whereas "chhaka" was, on average, second or third (average rank 2.40) in their listing.

is that of the helpers who are an integral part of the trucking population. Several past studies have suggested that truck drivers often turn to their helpers (khalasis) for sex, sometimes including coercive, exploitative practices. Another important category is that of "young boys," of which laundas is a frequently used label, but the original list of 50 also include "boys on the road," "boys in the dhabas," "young boys engaged in vending" and others.

Altogether, if we added up all the different mentions of "boys" (including laundas) the total comes to 53 mentions, not counting the helpers. 
Recent studies have pointed out that under the label, "MSM" there are wide variations in the types of persons, and the types of situations, that are involved (Asthana and Oostvogels 2001; Chakrapani et al. 2002; Kulkarni et al. 2004). This generalization is of central importance for understanding these phenomena, and for planning interventions. This same generalization applies to MSM activities among drivers and their helpers in the trucking population. While some individuals refer to same-sex activities between drivers and their helpers (khalasis), almost all of our informants referred to sex with hijras, in addition to which there were many references to other types of males, who were neither hijras nor helpers. Many of the truckers referred to having sex with "boys" (e.g. "laundas"), which is a reminder that MSM activities are not only "man to man." Whatever the actual percentages of truckers who are involved in same-sex activities, it is important to understand their different patterns of behavior and attitudes.

\section{Strong compulsions to engage in sexual activities: Release of body heat or garmi}

In the various interviews, truck drivers and khalasis frequently expressed the idea that their work situations produced especially strong compulsions to engage in sexual activity while "on the road." One major factor is of course their long absences from their families. Typically most drivers and their helpers are away from their home base, and wives and families, for weeks at a time, and many report longer periods of many months away from home. Informants spoke of sex as a natural "hunger," similar to that for food. "Like one hungers for food, in the same way one hungers for sex also" (jaise khane ki bhook hoti hai, waise sex ki bhi bhook hoti hai), according to one driver. Similar statements were repeated by several informants.

An additional component of "sexual compulsion" among truckers is the widespread idea that the situation of driving itself, whether in hot weather or not, produces "garmi" ("heat") which needs to be discharged through sexual activity. The concept of "garmi" or "garam pani" (meaning "hot semen") was mentioned by many of our informants as a major reason for engaging in sex.

For getting down the heat from the body. For entertainment... as living separately from the family. On discharging the heat from the body one feels much more enjoyment.

(Helper, unmarried, 25 years old.)

Sex is necessary for every human body after reaching a certain age. For getting down the heat, drivers and helpers do sex...

(Driver, unmarried, 23 years old).

People engage in... sex activity to get rid of the heat (garmi utarne ke liye ...) Also, if there is too much semen (maal) collected in the body then one will have problems in relation to the body heat (garmi ki bimari). (Driver, married, 30 years old).

Rao and associates, in their study of truckers in West Bengal, reported that their informants "perceived two different links between driving and sexual desire: (I) driving generates 'body heat'; and (II) tiredness caused by driving demands sexual relief" (Rao et al. 1994). 
There are additional factors that contribute to the high levels of sexual activity among truckers. The truckers encounter significant numbers of halt points - at the "octroi stations" (customs checkpoints), and at their loading and unloading areas. The stopping time at such halt points can range from a few hours to several days, so those are periods of enforced idleness. The truck halt places, some of which have hundreds of trucks at any time, day or night, attract numbers of vendors, and other people seeking to sell their wares in this "captive market." These also include sex-workers seeking opportunities to sell sex.

Yet another factor that is particularly conducive to same-sex activities is the small physical space within the trucks themselves, in which drivers and their khalasis often sleep or rest together. The possibilities for MSM activity are also strongly affected by the power relationship, in which the khalasis are extremely dependent on their drivers, not only for their daily food, but to teach them driving so they can move up to a well-paying occupation.

\section{Engage in same-sex activity when female partners are not available}

When asked for the reasons or motives for same-sex activities, one common response from our informants was "...when there is less availability of females for sex." Sometimes that statement of less availability was followed by a comment that female sex workers also cost more than sex with males. One informant, reported: “I didn't get a female sex partner so I had sex with a hijra." When informants were asked which was more enjoyable, sex with a male or sex with a female, many of them said that sex with a female is more enjoyable, if available.

The pleasure you get in having sex with a woman at home you don't get anywhere else...take her out, have fun with her. You can spend...3 to 4 hours.

(Driver, unmarried, 28 years old).

If females are not available then helper and hijra become his new sex partners.

(Key informant).

Sex with female at the age of 15 was most

pleasure... With female I did with love... with male I

did just for sex...after ejaculation I said bye and walked away...It is more pleasurable to do with females.

(Driver, unmarried, 27 years old).

At the time of requirement [sexual urge] when there is no availability of female for this purpose ...

consequently we establish homosexual rapport with the boys.

(Driver, married, 29 years old).

Some of the truckers expressed the idea that sex with females is natural, whereas male to male sexual activity is not natural, and hence less desirable.

God has made females for males, that is why sex between male and male is a crime.

(Driver, married, who said he had sex with a male two times before he got married, but denies any MSM activity since marriage).

The following excerpt from interview notes illustrates both the idea that sex with "a male is "unnatural," and the compulsion to engage in MSM activities if a female is not available: 
Interviewer: What is your preferred type of sex?

Informant: I am enjoying with women.

Interviewer: Why women?

Informant: Woman is natural sex.

Interviewer: Why not men?

Informant: I am doing, but it is unnatural.

Interviewer: If it is unnatural why you engage in it?

Informant: Garam pani bahar karne ke liye. (To get out the "hot water.")

Interviewer: What is "garam pani?"

Informant: It is dhaat (semen).

(Helper, unmarried, 20 years old).

\section{Belief that anal sex with males gives more pleasure and is safe}

Despite the fact that many of the informants stated a preference for sex with a female, when available, most of them spoke of sex with males as very pleasurable. The most frequent explanation given for the attractiveness of same-sex activity was that the anus is much "tighter" than the female vagina, and that tightness was experienced as giving more pleasure.

Interviewer: Why are you interested in anal sex?

Informant: Because anal sex is very tight action. So tight ka maza kuch aur hai. (Tight sex gives more pleasure.)

Interviewer: Have you done different type of sex?

Informant: Yes, I have done sex with a randi (female sex worker), randi ka loose hota hai (her vagina is loose) so not getting pleasure.
Nowadays I am not doing vaginal sex. I

am searching for fresh [sexually inexperienced] ladies, but not getting. Remaining are not fresh, so gand marna achcha hai (anal sex is good).

(Driver, unmarried, 32 years old).

Another driver added a further explanation for his observation that anal sex gave a more pleasurable experience than vaginal sex:

Interviewer: What difference did you find between sex with a male and sex with a female?

Informant: Male anus is very tight. It is painful and difficult to penetrate. But at the same time it is more fun and pleasurable maza ata hai.

Interviewer: Why it is pleasurable?

Informant: Ejaculation happens after long time - khel lamba hota hai.

(Driver, married, 30 years old).

Another very important motive that appears from the interviews for same-sex activity, particularly anal sex, was the belief that anal sex is "safe sex." Most of our informants were well aware of the spread of HIV/ AIDS, which they associated almost exclusively with female sex workers, reflecting the prevalent forms of AIDS awareness campaigns. Therefore, the great majority of our informants reported that condoms should be used whenever one has sex with females, and furthermore, that sex workers nowadays almost all carry condoms and insist on their use. On the other hand, only one or two of our informants said anything about condom use during anal sex, and most said it was "unnecessary." 
AIDS is with females. That is why I do not do sex with females.

(Driver, married, 30 years old).

Anal sex means it is safe sex, so I am not using condoms during same-sex activity. Most people are not doing sex through anal, so it is safe.

(Driver, unmarried, 32 years old).

They do it (anal sex) because if they do sex with females then diseases will catch them. But it they do sex with males, there will be no disease.

(Driver, married, 37 years old).

\section{Some truckers express a preference for same-sex activities}

Although the majority of our informants appeared to prefer sex with females, there were a few who appeared to prefer sex with males, and informants mentioned truckers who they said were oriented more to MSM than to heterosexual contacts.

An unmarried driver (24 years old) stated that he had had sex with a great number of different males and hijras. He made a distinction between the two, saying that he had not had sex with a male for the past two years, but he had had sex with a hijra just two months back. Although he mentioned frequent sexual activity with many different partners, he never mentioned sex with females in his narrative.

The following statements by key informants were made in the context of referring to a small minority among the truckers:

My friend says that he gets much more enjoyment of sex if he does this with boys than with [his] wife.

(Driver, married, 29 years old).
There are some people who have got habituated with this so they enjoy only with male sex. They don't like females. They are called "gandava".

(Driver, married, 30 years old).

Another informant told of a driver acquaintance from north India who, although married with two children, "would get erect only with hijras and males. Whenever he would go to females, his penis was not getting erected."

\section{Some truckers seem to be "bisexual"}

A 23-year-old truck driver expressed the view that, after reaching a certain age, every individual needs to have sex: "You can take an example of hungry person and like that everybody has a need of sex." His view was similar to that of several others, who said that the need for sex was much the same as the need for food. When asked about his sex partners, he answered, "I like sex with hijras, boys and women." On being asked about the special characteristics of his preferred sex partners, he said that they "should be of tender age, smart, fair and just like women in appearance." The interviewer then asked him about hijras, and he said that they are "just like women," therefore he finds them attractive.

The attitudes of several other informants seemed to be the same, as they made no sharp distinctions concerning sexual relations with those three categories. These men generally express no hesitancy about engaging in same-sex activity. To some extent their styles of sexual behavior include the concept of frequent changes of partner and exploring new sexual experiences. A few of the respondents spoke of 
the fact that sex with males can include a wider range of sexual practices, partly reflecting the fact that both female sex workers and the wives of the truckers generally resist engaging in anal and oral sexual acts.

A 30-year-old married driver was quite emphatic about his belief that sexual urges or appetites must be heeded. The following excerpts exemplify this type of opinion:

Informant: It is difficult to control the urge for sex. The meaning of same-sex behavior is to fulfill the sexual needs somehow.

Interviewer: Do you engage in sex with males the same way you do sex with females?

Informant: Yes, we do the sex with them the same way we do with females. If wife (aurat) is there at home then we do sex with her. If we do not find females outside then only we do sex with males. Then slowly we get habituated to it because we have to meet/fulfill the need for sex.

\section{Hijras as sex partners: a major pattern}

In addition to the free list data, above, we found that hijras were the most frequently mentioned sex partners in the in-depth interviews. Twenty-four of our 32 "case" informants had had sex with hijras, and among "most recent sex partners," nearly half (15) individuals listed hijras. The significance of hijras as sexual partners is further evidenced by the fact that there are quite a number of different labels or terms used by the truckers to refer to them. These include chhaka, janka, mehera, janani, maigoli, jhaduvo, juggar, yashoni, bhavesh. Probably other labels are also used in some sub-groups.
An important reason for preferring sex with hijras is that "they look more like women," compared to other male partners. That of course is partly a reflection of the fact that the hijras dress as women and wear make-up. One informant mentioned that the hijra "should have breasts and be of tender age and fair..." Another said:

...sex partner should be of tender age, smart, fair and just like the women to look at. Hijra is the same, just like the women.

(Driver, unmarried, 23 years old).

A 20-year-old helper replied in this way concerning the preferences of truck drivers for "female-looking" sexual partners:

Interviewer: Does a driver like a chhaka [hijra] or a male?

Key informant: Drivers like chhaka because they look like females. And the other names for chhaka are hijra or paune aath.

Several of our informants said that, compared with female sex workers, the hijras charge less money. The amounts mentioned were "30 to 50 rupees," and sometimes up to 70 rupees. None of the informants mentioned paying more than 100 rupees. Sex workers, on the other hand, often charged 100 rupees, and sometimes much more. Of course the amounts varied widely, depending on the locations, and the physical attractiveness of the sex workers.

The following description, by a 23-year-old unmarried helper, is typical of a number of narratives of both drivers and helpers. We note in the narrative that the informant was not particularly looking for sex at that time, but was approached by the hijra. 
My recent sex partner was hijra, which I had done six months before without condom. In course of sex, I did kissing, pressing the breast and anal sex. For smoothness, I had used mustard oil at the time of sex... I was sitting alone and hijra came up to me here at the electricity office, Azadpur [Azadpur mandi area in Delhi], and my soul permitted me to do sex and accordingly I did that. There was no need of a mediator and I paid the charge of Rs 30.

When truckers were asked where they would locate or find the hijras, the Azadpur mandi area was the most often mentioned as a location frequented by hijras. One key informant said: "They are available everywhere. Here in Varanasi their availability is less. They are available outside Bareilly, Delhi and also in Gujarat. You can find them anywhere...." Another key informant said that at the "Sanjay Gandhi Transport Centre (Delhi) and in Ghaziabad. you have plenty of hijras available for Rs 50." Our informants reported that in most locations hijras do not rely on any intermediaries or "dalals" for contacting their clients.

In south India hijras are often associated with the management of bathhouses, or hamams. A recent article in the New York Times reported observations at a very large truck halt area at Nelamangala, 9 miles $(14.5 \mathrm{~km})$ north of Bangalore, around which there were reported to be over 40 hamams. The news item described the Sangeetha Hamam, operated by a 28 year-old "eunuch," wearing lipstick and a black dress. "Her customers - as many as 100 on Sundays for her and five other eunuchs - come for a 'massage' and the anal sex that follows, but also for the anonymity the location confers...."The customers are not just truckers, "but also Bangalore college students and other city residents." (Waldman 2005).

\section{Khalasis: often sexually exploited, but some are willing participants}

Practically all studies of the sexual behavior of trucking people make reference to sexual contacts between drivers and their helpers (khalasis). The helpers are in a particularly vulnerable situation as they are generally quite young and inexperienced, and they are totally dependent on their drivers for food and other necessities. Young boys become khalasis in order to learn driving, hoping to enter into that more prestigious and well-paid occupation. Although some drivers are said to be generous with their helpers, and several denied having any sexual activities with their khalasis, many of our informants told of sexual exploitation of helpers, sometimes involving violence. The most usual answers to questions about sexual exploitation and violence were references to exploitation of helpers by their drivers. The following exchange illustrates the vulnerable situation of the helpers:

Interviewer: Who do they have for [male] sex partners?

Informant: They do sex with their own conductors [khalasis]. (Apne conductor ke saath karte hein).

Interviewer: Do the conductors consent to the sex?

Informant: If they don't agree, drivers will do it forcefully. If the conductor does not agree, 
the driver will ask him to go away or driver will leave him in the middle of the jungle. Out of compulsion the conductor agrees with driver [to have sex].

Interviewer: Have you ever heard about violence [in these situations]?

Informant: I have not only heard, but also I have seen it many times. Once I had to give lift to a helper in my truck. Driver asked helper to do it [sex]. He asked conductor to remove his clothes so that he can penetrate him. He didn't agree [so driver left him...] (Driver, married, 37 years old).

In some cases, the sexual abuse of the khalasis may involve other perpetrators besides the driver of that particular khalasi, as in the following narrative:

I stayed at a Dhaba which was $15 \mathrm{~km}$ from the place of Maihar (in Madhya Pradesh). At least 8 to 10 truck drivers with their trucks had stopped there. Suddenly a loud noise came at 1:00 o'clock at night... and I came to know that three truck drivers have done sex with one khalasi and the latter was weeping and all [the truckers] had fled away from there.

(Driver, married, 29 years old).

Sometimes drivers make cleaners/helpers drink, once they are drunk, drivers do sex with them.

(Driver, married, 35 years old).

Other informants reported that some drivers select as their khalasis young boys who are amenable to having sex with them, so that coercion need not arise. In the following example the informant (driver) made it clear that he does not engage in such activities.
Interviewer: Do they have sex with helpers?

Informant Yes, people keep outside people as helpers, those who are good-looking and have weakness towards sex. But I keep people from my own village as my staff. Since we keep money with ourselves in the vehicle, trusted person is very important. I have never kept somebody by thinking on sex lines.

(Driver, married, 35 years old).

Some informants commented that the sexual relationship between driver and his khalasi may be a long-term arrangement, based on the helper's desire to gain driving skills and knowledge. On the other hand, the supposed "contract" of teaching the helper to be a driver may sometimes be unfulfilled:

So many times, it has been seen that driver establishes the homosexual relationship with his helper and this rapport remains in force for a long time. The reason of this long-time relationship is that the truck driver tells the helper that I will teach you how to drive the truck and consequently the helper agrees with his driver's intention in compulsion situation. When the former satisfies his requirement with the latter and does not discharge his commitment which he has made earlier with his helper of teaching driving, dispute between them arises and the final result is that the driver dismisses the helper.

(Driver, unmarried, 23 years old).

Some of the informants described relationships between drivers and their helpers in which the helpers were described as willingly participating in the sexual activities. In some cases, according to informants, helpers assumed the "penetrating role." 


\section{Sex with laundas (boys)}

The subject of sex with young boys came up many times in the interviews concerning same-sex activities. A driver who spoke of the types of young boys they find most attractive (including the young boys who are khalasis in the trucks), commented: "Till the time beard and moustache appear, even females fail before males." By which he meant that sex with attractive young boys is preferable to sex with females.

The interviewers asked drivers and khalasis about what characteristics they particularly looked for in young boys. Typical replies were like these:

A boy (ladka) should be between 15 to 18 years of age... a boy of that age does not have any moustache or beard and they are clean (chikna) also. He should be fair in colour (rang gora ho). (Driver, unmarried, 24 years old) .

They prefer smart, handsome, clean and fit guys...(saf ho, sundar ho, phurti ho) They prefer boys between 15 to 22 years of age. Not more than this. More than 22 years old male does not give pleasure, as his beard and moustache start appearing."

(Driver, unmarried, 27 years old).

The informants said that they find young boys at the dhabas and lodges along the highways, besides beggar boys, street vendors and others. One informant commented that his driver likes Nepali boys, as they are young and good-looking:

One can get the boys at hotels. There some boys of tender age working at hotels who are also interested to be involved in this work [sex] but not all of them. (Driver, married, 27 years old).

\section{Feminized men as sex partners}

The respondents used terms such as gandus, kothis, maichias, paune aath, number 6 and 81 to refer to males who are thought be amenable to participating in MSM sexual activity, in part because they are considered "feminized," and therefore seeking to have sex with "masculine men." Of these, kothis are the most widely mentioned in MSM literature and research in India, as that label is known throughout most of India, referring to feminized males, many of whom dress in women's clothing, and wear cosmetics, particularly when engaged in sex work activities.

Since kothis sometimes dress as females when they are seeking sexual partners, it is likely that the truckers may not always distinguish between hijras and kothis. However, most of these somewhat "feminized" males (e.g. gandus) dress in male clothing, and refer to themselves as males, in sharp contrast to hijras.

\section{Bawasir: an unusual type of sex partner}

The word "bawasir" appears to refer to hemorrhoids or "piles" or perhaps other problems of itching or inflammation in the anal region. Several informants stated that men suffering from "bawasir" obtained some kind of relief from being penetrated in anal intercourse. Informants described encounters in which men with bawasir offered themselves for anal penetration.

Interviewer: Why do men engage in same-sex activity? 
Informant: One reason is that those people having

"bawasir" do it. This is such a reason

that you will find most of the people in the truck line do it for this reason.

(Key informant, driver).
Several informants expressed a common theme, which includes the idea that certain types of sexual intercourse can "cure" STIs. The following statement is an example:

Table 4: Types of same-sex acts engaged in by men, as listed by respondents (No of respondents 111)

\begin{tabular}{|c|c|c|c|c|c|}
\hline & Item & Frequency Resp & $\%$ & Avg Rank & Smith's S \\
\hline 1 & ANAL SEX & 96 & 86 & 2.083 & 0.636 \\
\hline 2 & KISSING & 59 & 53 & 2.593 & 0.366 \\
\hline 3 & ORAL SEX & 51 & 46 & 2608 & 0.273 \\
\hline 4 & MASTURBATION & 44 & 40 & 3.295 & 0.195 \\
\hline 5 & CARESSING THE BODY & 38 & 34 & 3.316 & 0.189 \\
\hline 6 & CARESSING THE BREAST & 30 & 27 & 3.033 & 0.164 \\
\hline 7 & CARESSING THE PENIS & 25 & 23 & 2.360 & 0.164 \\
\hline 8 & HOLDING EACH OTHER & 21 & 19 & 3.286 & 0.105 \\
\hline 9 & LICKING & 19 & 17 & 2.895 & 0.100 \\
\hline 10 & VAGINAL SEX & 10 & 9 & 2.400 & 0.053 \\
\hline 11 & FINGERING THE ANUS & 8 & 7 & 3.125 & 0.045 \\
\hline 12 & CARESSING THE CHEEKS & 7 & 6 & 2.714 & 0.041 \\
\hline 13 & THIGH SEX & 5 & 5 & 3.800 & 0.021 \\
\hline 14 & KISSING THE NIPPLES & 3 & 3 & 4.667 & 0.014 \\
\hline \multirow[t]{2}{*}{15} & RUBBING THE PENIS ON & & & & \\
\hline & THE ANUS & 3 & 3 & 5.333 & 0.010 \\
\hline 16 & HOLDING HANDS & 2 & 2 & 3.000 & 0.011 \\
\hline 17 & LICKING THE ANUS & 2 & 2 & 3.500 & 0.009 \\
\hline 18 & RUBBING OIL ON THE PENIS & 2 & 2 & 3.500 & 0.009 \\
\hline 19 & RUBBING PENIS ON THE BODY & 2 & 2 & 2.500 & 0.010 \\
\hline 20 & CARESSING THE THIGH & 2 & 2 & 5.500 & 0.009 \\
\hline 21 & FINGERING THE VAGINA & 1 & 1 & 3.000 & 0.005 \\
\hline 22 & CARESSING HAIR & 1 & 1 & 3.000 & 0.005 \\
\hline 23 & KISSING THE CHEEKS & 1 & 1 & 4.000 & 0.005 \\
\hline
\end{tabular}


There is another reason [for MSM activity]. It is called "bawasir". There are two types of bawasir: 1. plain bawasir; 2. gumundi bawasir. People having plain bawasir would like to get penetrated. The second category of people have "phode" [boils and blisters in anal region]. To get rid of this they do sex with another man.

(Driver, married, 37 years old).

Although two persons mentioned going to seek medical services for bawasir, it appeared that most men with that condition do not seek medical treatment, partly because they would be too ashamed to present their case to doctors. It is likely that even greater stigma is attached to anal complaints than to infections in the genital region.

The fact that 15 people mentioned bawasir in the free lists (Table 3 ) suggests that the condition, and the related sexual practices, are fairly common among trucker populations. Key-informant interviews give further support to the importance of this aspect of male-to-male sexual behavior.

\section{Sex acts}

The interviewers asked the respondents to list the types of sex acts in same-sex encounters. Table 4 shows the range of sex acts mentioned by the informants and their "centrality" in terms of frequency of mention.

From the table it is clear that anal sex is the sex act of greatest "salience" or centrality. At the same time, it is important to note that respondents mentioned 23 types of sex acts that men engage in (with vaginal sex also being mentioned as one of the acts). Of all the sex acts, penetrative sex appeared dominant in both frequency and ranking - anal and oral sex acts ranked as 1 and 3 respectively.

Foreplay and non-penetrative acts are important for truckers in same-sex behavior The respondents mentioned a wide range of non-penetrative sex acts that indicate the importance of these acts in their same-sex encounters. Acts such as kissing, masturbation, caressing, and hugging are high on the list, with kissing between men ranked as 2 . In interviews, most of the respondents mentioned that with their male partners they usually engage first in non-penetrative acts in order to excite and arouse themselves and their partners, after which they engage in anal or oral sex.

My partner (hijra) started massaging and holding my penis then I came in mood for sex. Then I started pressing the breast and massaging the whole body, I bit his cheeks, pressed the whole body and later I did anal sex with the hijra.

(Driver, married, 29 years old).

While females have breasts, males don't have breasts. So two men caress each others' body with their hands. By doing this, they feel like having sex. By touching the body, it becomes "hot." Then I do kissing, put on condom and penetrate from the "back". (Driver, unmarried, 27 years old).

He kissed me on my cheeks, caressed my face with his hands, then rubbed his penis on my anus, fondled my breasts and then did anal sex with me."

(Helper, unmarried, 18 years old).

The respondents were also asked about use of condom and lubricants during penetrative same sexual act. The majority of respondents mentioned 
they did not use condoms with their male sexual partners as they did not perceive risk of infection.

Drivers don't use condoms with helpers as they don't see any health risk. They feel if they wash their penis they will not get any sexual disease. They think they are the only ones who have sex with us so we are not infected.

(Helper, unmarried, 24 years old)

Some of the respondents also mentioned that they felt condoms reduce pleasure and thus they do not like to use it.

Most times I do not use condoms. I don't think it is necessary to use them - nothing happens. I do not get much pleasure when I use condom. Without condom I get great pleasure (khula karne per jyada anand aata hai).

(Driver, married, 32 years old)
Most of the respondents mentioned using some form of lubricant for anal penetrative sex, regardless of condom use. When they were asked about the type of lubricant used the responses varied from spit to grease to brake oil to cooking oil.

Sometimes we use grease, mustard oil, sande ka tel (herbal oil). People sell sande ka tel for curing headache and we buy it and keep it. When we have sex we use this oil. Oil is more lubricated and condom is not as much. That's why I like oil.

(Driver, married, 32 years old)

I used spit for lubricant. It was good. But initially when I had problem I had used coconut oil.

(Helper, unmarried, 20 years old) 


\section{Health Problems and Treatment Seeking}

\section{Sexually transmitted infections (gupt rog)}

Almost all the drivers and helpers interviewed had heard of STIs or gupt rog, as well as HIV/AIDS. When asked to identify some signs and symptoms of gupt rog most of the respondents mentioned boils and blisters on the penis, burning and inflammation of the penis, burning on urination, etc.

The symptoms are ...discharge from penis (dhat girna), swelling (sujan hona), burning during urination (pisab mein jalan hona), swelling of the nerves (gudi phul jana), and blistering (ghawo hona).

(Driver, married, 26 years old).

The signs of STD are discharge from penis (dhat girna), boil on penis (ling pe phunsi hona), burning on urination (pisab jalan hona), inflammation of the penis (ling phul jana) and swelling of the penis (ling pe sujan hona).

(Driver, married, 35 years old).

Most of the drivers and helpers mentioned having had some of those symptoms of STIs. When asked to mention symptoms they had experienced, those commonly mentioned were itching, sores and ulcers on the penis, and "burning during urination."
Once I had itching problems and ulcer in the penis. (Driver, married, 29 years old).

Burning sensation during urination and sores on the penis.

(Driver, married, 30 years old).

Ek bar hamko ye hui thi (Once I had this disease). Why should I lie? I had sex with "randis" (female sex workers) in Madras. I did it around 11'o clock at night. In the morning my penis was burning. Urine came slowly. It was painful. Then some "dane" (pimples) came.

(Driver, unmarried, 28 years old).

\section{Treatment avoided due to embarrassment}

Some respondents mentioned that despite their symptoms they did not seek any treatment owing to either embarrassment or shyness about consulting a provider with whom they might have to share that they had indulged in a "galat kaam" (wrong act).

I did not seek help for my disease as I was embarrassed to go to a doctor.

(Driver, married, 30 years old). 
Now I am suffering with wounds on my penis. I was very scared and feeling shy to disclose it to others. (Helper, unmarried, 20 years old).

I had blisters on my penis, discharge from penis, burning sensation during urination. I did not take any medicine for this. Neither have I got my blood tested. (Helper, married, 24 years old).

\section{Treatment from trained health providers}

Despite the embarrassment, it appears that some of the respondents consulted qualified doctors either available at the TCIF clinics or in private settings.

My urine route was always burning. I then went to the TCI clinic in my halt point. To get cured for burning urination I had taken medicine for complete 14 days. Now I am fine. I got fully cured. (Driver, married, 26 years old).

At first I was embarrassed but then went to a doctor who said that I have STD (youn rog), gave me medicines and after taking them I became okay. (Driver, married, 30 years old).

I had blister on penis, burning in urine etc. I got medical treatment and became well. I got allopathic treatment in Kolkata. I had got HIV test in Kolkata itself and my report was normal.

(Helper, unmarried, 24 years old).

\section{Other treatment for gupt rog}

Some of the drivers and helpers interviewed mentioned going to unqualified providers for treatment as well as trying various home remedies and some very unusual ways of curing themselves of their sexual health problems.
I take medicines from the "quacks" (jhole jhapa) who roam here and there with their bags. If there is some problem on the penis then I put oil. (Ling per ghao hone se tel laga dete hain).

(Driver, married, 31 years old).

Some of the respondents mentioned other popular myths about prevention of or cure for STDs that they practiced.

Some people wash their penis with their urine. People say that if one washes with urine, then one never gets infected. Many people do this.

(Driver, married, 32 years old).

Boils and blisters on the penis get cured if you do sex with donkey or dog. I have done with the dog (female) in my village. She was our own dog. I had very limited knowledge that time. As I had severe itching on my penis, I did sex with the dog (female) and it got cured. (Driver, unmarried, 27 years old).

\section{Awareness of HIV/AIDS is widespread, but misconceptions abound}

When the respondents were asked what they knew about HIV/AIDS the responses were mixed. Many men mentioned they had only heard about this khatarnak bimari (dangerous disease) through various media channels including radio, posters, pamphlets and friends, but most did not know much about the disease.

Three months back I had my last sex act. Nowadays I don't do it any more because there is some disease going on. The disease is known as AIDS. I do not have any idea about the disease. I have only heard about the disease.

(Driver, married, 31 years old). 
I have heard about it (AIDS) in many places. I do not know anything else. If you have sex then you get AIDS. If you do not do sex outside (with sex workers) then you can not get it.

(Helper, unmarried, 18 years old).

I don't know about prevention. Whoever does it (sex), will die of course (Karega to marega sala aur kya). (Driver, married, 26 years old).

As mentioned above, many of the informants associated the risks of getting HIV infection especially with female sex workers and thus reported using condoms only with them. At the same time, they mentioned that they don't use condoms when they have sex with men:
When we go to randis (female sex workers) we put double nirodh...

(Driver, unmarried, 28 years old).

I don't use condoms with boys but only with girls.

(Helper, unmarried, 20 years old).

I have used condoms with sex workers (baisyas). I have not used condoms with hijras... There is no need to use condom with hijras as the penis does not go fully inside the anus. When I do sex with sex workers, I always have the fear of HIV/AIDS. They are bad as at least 10 people do sex with one sex worker every day. (Driver, married, 33 years old) 


\section{Discussion}

This exploratory research has disclosed evidence of very complex patterns of same-sex behavior among the truckers interviewed at the five study sites. These data show that there are many different types of male sex partners involved, a wide range of sexual acts, and extremely diverse locations and situations for MSM activities. Previous research has often identified the helpers or khalasis as sexual partners of truck drivers, but our data-gathering identified many other types of MSM partners, of which hijras were the most frequently mentioned by both drivers and the helpers. Other frequently mentioned types of partners were kothis and other "feminized males," young boys and there is a special category of men seeking anal penetration because of 'anal itching' labeled as bawasir. This last group of people believe that the discomfort/itching is relieved when they are penetrated during anal intercourse.

Anal sex appeared to be the most preferred sex act, according to these interviews, but the informants also described non-penetrative sex acts such as kissing, caressing, body rubbing and masturbation. Oral sex was also frequently mentioned. Very few informants reported condom use in same-sex penetrative contacts, and most of them believed that anal sex is "safe sex," in contrast to the dangers of serious infection from vaginal sexual contact with female sex workers.

Coerced or non-consensual sex seems to be indicated, especially in relationships between drivers and their khalasis. Also, as some truckers did mention seeking or preferring sex with 'boys' or laundas, there might be elements of coercion in these age and power differential relationships which warrant further exploration.

\section{How frequent is MSM activity among the truck driver/khalasi population?}

Actual frequencies are extremely difficult to estimate, because of the stigma associated with MSM activities. There is sure to be much denial (hence underreporting) of such activities during surveys. The data from the rural sexual behavior study (Verma and Collumbien 2004) suggest the proportion of persons involved in MSM activities to be above 10 per cent. The one earlier study (Rao et al. 1994) produced much higher numbers, with approximately 30 per cent of their respondents reporting male-to-male sexual acts. This earlier study by Dr Rao and her colleagues 
benefited from good conditions of rapport and

skilled interviewing.

The statements of our informants in this study, and similar findings in other studies, point to several ways in which the situation of truckers, far from their homes and families, is strongly conducive to sexual activity. The beliefs of the truckers, concerning the need to "discharge the garmi" are linked with the ready availability of sexual partners (sex workers and others) along the highways and at the halt places frequented by truckers. All the available data suggest that truck drivers and their helpers engage in frequent sexual activities, between themselves and with a wide range of different kinds of partners "on the road." We suggest that estimates of the percentage of truckers engaging in MSM activities are likely to be close to those found in the study by Rao and colleagues.

\section{Are MSM activities among truckers increasing because of the fear of HIVI AIDS?}

The present study is, of course, only an exploratory one, and it would require a much larger, more complex study to answer this question. However, several respondents interviewed during the course of the study suggest that truckers are reducing contacts with female sex workers, and are instead seeking male sexual partners. The following items are suggestive of that development:

1. Data from the free list on sex partners (Table 3) clearly indicates that truckers, when on the road, have significantly more male sexual partners than female sexual partners.

2. Some informants directly stated that they avoided sex with female sex workers, for fear of HIV/AIDS, and are therefore turning to MSM sexual contacts. The truckers' belief about female sex workers being the only dangerous source of AIDS is understandable as most AIDS awareness campaigns have specifically identified female sex workers as "dangerous," and have for several years promoted condom use most especially in connection with female sex workers. Also some men said they did not want to use condoms, and nowadays, they said, most of the female sex workers insist on condom use.

3. The fact that most AIDS awareness programs have not focused on MSM sexual activities has indirectly fostered the belief that sexual contact with same sex partners is not risky. Almost all informants were convinced that anal sex with males is "safe sex," and therefore did not warrant use of condoms. This persistent claim about the supposed "safety" of anal sex is perhaps the most compelling part of the evidence

4. Earlier reports of MSM activities among truckers referred mainly to sex with the khalasis. For example, the study by Rao and associates makes no mention of hijras or other types of male sexual partners, which suggests that the earlier MSM activities were largely between truck drivers and their helpers. 


\section{Implications for Intervention Programs and Further Research}

The study identifies the patterns of same-sex sexual behavior of truckers that need to be addressed in HIVprevention interventions, which hitherto have been largely ignored by policy-makers and program implementers.

\section{The high risks of unsafe same sex}

behavior should be a key focus area in HIVprevention efforts with men, and particularly with trucker population.

So far same-sex behaviors are mainly addressed by intervention efforts working specifically with MSM sub-populations. It is clear from this study that truckers who do not identify themselves as MSM, engage in same-sex acts with a variety of partners, with a large majority of them engaging in anal penetrative sex. While the proportion of truckers who engage in same-sex acts is not established, it is clear that these patterns exist and need to be recognized by program implementers. Truckers also believe that anal sex is 'safe sex' and thus do not perceive the need to use condoms during same sex penetrative sexual acts. It also appears that truckers may be reducing contacts with female sex workers, and are instead seeking male sexual partners. These misconceptions, a reflection of the ways in which information about safe sexual practices is conveyed through AIDS awareness and outreach campaigns must be corrected to prevent the transmission of HIV infection. The same messages and efforts also need to be directed to the various categories of persons who are the usual sex partners of the truckers that includes the hijras, kothis, hotel boys, and others along the travel routes of the truckers.

At the same time, because of the sensitive nature of MSM activities, which are even more stigmatized than heterosexual contacts with female sex workers, programs should develop non-threatening and nonjudgmental messages and pathways for awarenessraising and direct counseling among trucker populations. One of the first steps could be to sensitize program staff and outreach workers involved on HIV prevention activities on MSM issues so that they are comfortable and knowledgeable in working with people who report engaging in same sex behaviors.

Violence and coercion in same sex relationships has also been reported by some of the truckers and efforts need to be made to explore this further as well as develop strategies to address it. A starting point may be to orient program staff to probe and recognize incidents of sexual violence and refer those who have experienced violence for counseling and support services. 
These findings can be incorporated in the existing program communication strategies adopted by Project Kavach. These are as follows:

- Peer-led, dialogue-based interpersonal communication: The TCIF program has recruited and trained over 200 trucker peers at seven intervention sites covered by their program. Evidence from the field suggests that peers are more credible and acceptable to the key population than outreach workers and also a dialogue-based methodology is more participatory than a one-way didactic flipbookstyle messaging. There has been a regular dialogue on the driver-helper sexual equation in several sessions. In each location about 240 sessions are held in a month and thus provide an opportunity to discuss a range of issues that affect and concern the truckers.

- Magnet Theatre is an interactive mid-media method used by the program, where an audience of up to 300 truckers debates and offers solutions to an "unfinished" play, which presents a dilemma. One dilemma that has been enacted with enthusiastic participation from truckers was that of a helper who could not afford to leave his job though he was oppressed by the sexual advances of his driver colleague. Open discussion of such issues in a large forum affords anonymity and views get expressed freely and issues come out of the closet.

Through this medium, attempts will also be made to address and reorient the notion of "masculinity" in such a way that the focus shifts from "sexual prowess" as a surrogate for masculinity, towards safe sex and responsibility towards oneself, partners and family.
Information and services should be provided to truckers for detection and treatment of anal and oral STIs and their links with vulnerability to HIVIAIDS.

Clinics and other medical facilities should receive information and training to diagnose symptoms of anal infections, oral infections, and related problems arising among persons involved in MSM activities. This awareness of special features of MSM health issues should not be limited to clinics and providers along the truck routes, as the same issues also arise in other facilities utilized by males with STIs and other sexual health problems. Project Kavach has the clinic base that could be built on to handle these issues effectively. The program is investing huge resources in training medical doctors, counselors and nurses at of all its clinics and service extensions on handling of MSM issues in a non-judgmental, sensitive and confidential manner. Outreach workers and counselors should be provided with up-to-date information on the vocabularies of MSM activities, as well as the languages of reference regarding STIs and related health problems. Husmafar Trust (2006) has recently developed a 'Manual for Counseling MSM' (in print) in which one section details vernacular vocabulary and phrases that the counselors should be familiar with while providing counseling services to MSM. It may be useful to explore the need to develop a similar manual for counselors providing services to truckers.

Counselors at STI clinics in particular can be very effective in promoting the correct use of water-based lubricants (instead of the oil-based lubricants such as grease, oil, lotions, etc., that can damage the latex condom) along with condoms and providing information on the correct usage and necessity of using condoms, particularly during anal penetrative sex. 
It is clear that MSM issues among truckers are complex and programs need to address them comprehensively through appropriate integration of communication elements which are participatory and medical and counseling services that are confidential, non-judgmental and sensitive. Readers of this report, and persons/programs seeking to address the issues outlined here, should keep in mind that these efforts are intended to lead to more effective prevention of HIV/STI infections in key populations. These materials are not intended to stigmatize, or single out a population such as the truckers for criticism. The information contained here should make it possible to develop and enhance existing interventions to better reach the key populations with appropriate and comprehensive services.

\section{Some issues for further research}

This study was carried out in a limited number of sites, with relatively small samples of key informants and in-depth interviews. Evidence from the study highlights the need to undertake further research to better understand the complex patterns and dynamics of truckers same sex behavior and related HIV/STI risk. Some suggestions for further research are detailed below.

- The depth of personal and sensitive information collected during this study supports that similar methodology be used to examine these issues in a larger sample to get a better and wider representation of people from different areas and sectors of trucker populations. It is also time to undertake studies to assess magnitude of same sex behaviors among truckers by undertaking large scale random sample surveys. However, there may be a likelihood of under-reporting of such behaviors during survey style of datagathering. This has been evident from some existing surveys of trucker populations that resulted in low estimates of same-sex activities, which further resulted in design of current programs that did not address these aspects of risky sexual activities among truckers. Thus, to address this problem, key lessons learned from this qualitative study that should be applied in surveys includes focusing on refining questioning techniques and developing greater sensitivity among survey researchers prior to undertaking data collection.

For example, instead of asking one direct question about same sex behavior such as 'have you ever had sex with a same sex partner?', three to four warm-up questions may be asked in a non-threatening and non-judgmental manner. These may be as follows:

(1) 'Are you aware that when men get together they sometimes do masti of sexual nature with each other?' (2) Are you aware that this masti may sometimes be sexual in nature? (3) Do you know any man who has ever engaged in masti of sexual nature with another man? (4) Have you ever engaged in masti of sexual nature with another man? (5) If yes, when was the last time you did masti with another man? (6) What did you do with your friend/partner when you did masti with him - (a) masturbation (b) oral sex, (c) anal sex, (d) non-penetrative sex such as kissing, rubbing, hugging etc.

- In this study, when most drivers narrated their same-sex experience they almost always mentioned engaging in penetrative sexual act in 
which they took on the role of the 'active' partner and not as the receptive partner. It seems that male-to-male sexual behavior in this population may be linked with the construct of masculinity which is characterized by sexual dominance and power. This linkage needs further exploration to better understand the factors that determine risky sexual behaviors of the trucker population.

- The study also indicates that truckers may be seeking out male sexual partners at an increasing rate as compared to female sexual partners due to the various reasons elucidated in the report. This perceived change in sexual behaviors needs to be tested through further research.

- It is also evident that truckers who engage in same sex behaviors also report sex with female partners. The nature and risk of this concurrency of sexual partners wasn't explored in great detail in this study. If possible, an attempt may be made to compare sexual behaviors of those truckers who report engaging in same sexual activity with those who report engaging in sex only with females to examine potential risk to themselves as well as to their female partners. It would alsobeuseful to undertake an ethnographic study at the towns or villages of truckers to understand the sexual networking in these areas and related risk to both trucker and his partner/s.

- There is a need to better understand the dynamics of coercive and non-consensual sex among truckers and their male sexual partners. Research can be conducted to understand these experiences from perspective of both the perpetrators and those who experience violence.
- As truckers are not one homogenous group and thus it is important to develop a typology of truckers that is associated with their mobility or work pattern. For example, long or short distance truckers - this difference in mobility and work pattern determines the time spent away from home and family and may be associated with sexual risk taking behaviors. In addition, factors such as truckers regional background, substance use such as alcohol and drugs etc, should also be explored to understand their association with risk behaviors.

- As evident from the study, hijras and feminine boys (also referred to as kothis) were mentioned as the predominant or preferred same sex partners of truckers. No previous study had documented this and this may suggest that changes have taken place among key populations, particularly hijras (and kothis). This indicates a need to study the mobility histories of these key populations to examine if there is some movement to locations where they have more contacts with truckers. Such research would depend heavily on key-informant interviewing - of hijras and kothis at carefully selected locations, as well as other types of key informants (e.g. dhabawalas) who have knowledge about the sub-population configurations and behaviors over the past several years in their areas.

- Targeted intervention projects need to be evaluated to examine their impact on truckers sexual behavior, health seeking behavior and HIV related knowledge and attitudes so as to suggest ways to refine or strengthen interventions. 


\section{References}

Ahmed, S. 1992. Truck drivers are vulnerable groups in northeast India. Abstract published in The 2nd International Congress on AIDS in Asia and the Pacific. Randwick, Australia: AIDS Society of Asia and the Pacific, p. 195.

APAC (AIDS Prevention and Control Project). 2002. Behavior Surveillance Survey: Truckers and Helpers. Chennai: Voluntary Health Services.

Asthana, S. and R. Oostvogels. 2001. The social construction of male "homosexuality" in India: Implications for HIV transmission and prevention. Social Science and Medicine 52: 707-21.

Chakrapani, V., A. Row-Kavi, L.R. Ramakrishnan, R. Gupta, C. Rappoport, and S.S. Raghavan. 2002. HIV Prevention Among Men Who Have Sex With Men (MSM) in India: Review of current scenario and recommendations. Background paper prepared for SAATHII (Solidarity and Action Against the HIV Infection In India).

Humsafar Trust. 2002. www.humsafar.org/research.

Humsafar Trust. 2006. Manual for Counseling MSM (in print). Humsafar Trust. Mumbai
Khan, S. 1994. Cultural contexts of sexual behaviors and identities and their impact upon HIV prevention models: an overview of South Asian men who have sex with men. Indian Journal of Social Work 55: 633-46.

Kulkarni, V., S. Kulkarni, and K. Spaeth. 2004. Men who have sex with men: a study in urban Western Maharashtra. Chapter in 'Sexuality in the Time of AIDS' edited by Verma, Pelto, Schensul and Joshi. Sage Publications, India.

Nag, M. 1996. Sexual Behavior and AIDS in India. New Delhi: Vikas Publishing House.

New Era. 2002. Behavioral Surveillance Survey in the Highway Route of Nepal: Round No. 4. Report submitted to Family Health International/Nepal (Kathmandu).

ORG Centre for Social Research. 2003. Knowledge, Attitude, Behavior and Practices (KABP) Survey of Male Reproductive and Sexual Health Among Truckers and Cleaners/Helpers in three Cities of Jharkhand. Report submitted to CEDPA/India.

Orobuloye, I.O., J.C. Caldwell, and P. Caldwell. 1992. Diffusion and focus in sexual networking: 
Identifying partners and partners of partners. Studies in Family Planning 23 (6/1): 343-51.

Rao, A., M. Nag, K. Mishra, and A. Dey. 1994. Sexual behavior pattern of truck drivers and their helpers in relation to female sex workers. Indian Journal of Social Work LV (4): 603-16.

Ramakrishna, J., M. Karott, R.S. Murthy, V. Chandran, and P.J. Pelto. 2004. Sexual behaviors of street boys and male sex workers in Bangalore. Chapter in 'Sexuality in the Time of AIDS' edited by Verma, Pelto, Schensul, and Joshi. Sage Publications, India.

Row-Kavi, A. 1993. HIV/AIDS awareness in the selfidentified gay community and its implications. Paper presented at the workshop on Sexual Aspects of AIDS/STD Prevention in India, Tata Institute of Social Sciences. Mumbai.
Singh, Y., R. Joshi, G. Rastogi, and A.N. Malaviya. 1991. Truck drivers: Their possible role in disseminating HIV in rural India. Abstract published in The 2nd International Congress on AIDS in Asia and the Pacific. Randwick, Australia: AIDS Society of Asia and the Pacific, p. 196.

Synovate. 2004. Baseline surveillance survey among Truckers, sex workers and trucking community (Unpublished Report). Synovate and TCIF, New Delhi.

Verma, R., and M. Collumbien. 2004. Homosexual activity among rural Indian men: implications for HIV interventions. AIDS 18: 1845-47.

Von Reyn, C.F. 1990. Epidemiology of HIV infection in Africa. AIDS and Society 3(2).

Waldman, Amy. 2005.India Accelerating: An epidemic spreads. New York Times, 6 December. 